\title{
Evaluation of Oral Health Related Quality of Life and Satisfaction Outcome of Endodontic Treatment in Central India - A Cross Sectional Study
}

\author{
Dr Anup Bhaisare ${ }^{1}$, Dr Ashwini Patil ${ }^{2}$, Dr Manjusha Warhadpande ${ }^{3}$, \\ Dr Asha kalbande ${ }^{4}$ \\ ${ }^{I}$ (Ex Assistant Professor, Department of Conservative Dentistry and Endodontic, Government Dental College \\ and Hospital ,Nagpur ,Maharashtra University of Health Sciences, Nashik ,India) \\ ${ }^{2}$ (Assistant Professor, Department of Conservative Dentistry and Endodontic, Government Dental College and \\ Hospital Aurangabad ,Maharashtra University of Health Sciences, Nashik,India) \\ ${ }^{3}$ (Professor and Head of Department, Department of Conservative Dentistry and Endodontic, Government \\ Dental College and Hospital Nagpur,Maharashtra University of Health Sciences, Nashik,India) \\ ${ }^{4}$ (Associate Professor and Head of Department, Department of Dentistry, Government Medical College and \\ Hospital Yavatmal, Maharashtra University of Health Sciences, Nashik ,India)
}

\begin{abstract}
:
Background: Effectiveness of endodontic treatment and criteria of success have mainly been considered in terms of clinical outcome, and there is a lack of information of treatment outcomes from patients' perspectives. This study aimed to assess the impact of endodontic disease and treatment on the quality of life of patients and patient's satisfaction in relation to endodontic treatment and the association of these outcomes with the treatment provider (General Dentists, Postgraduates and Endodontist).

Methods: This Cross sectional study included 250 subjects. Patient-reported outcome measures based on oral health-related quality of life was assessed using the short form of the Oral Health Impact Profile (OHIP-17) using a questionnaire method that measured changes in quality of life after endodontic treatment and semantic differential scales that measured satisfaction with endodontic treatment. The patients completed the assessments before endodontic treatment and 1 month and 6 months after root canal obturation. A global oral health transition assessment was ascertained by a single (global) item rating of oral health improvement and clinical assessment mainly based on the Periapical Index (PAI) of periapical radiographs.

Results: There were significant changes in OHIP-17 scores over the study period after conventional orthograde endodontic treatment (from pretreatment- 6 months, postobturation) $(P<.001)$. Data were analyzed using Chisquare, multiple and logistic regression $(p<0.05)$, and Mann-Whitney $U$ test $(p<0.02)$. Patient reported preoperative factors(e.g., pain, sleep disturbances) affect quality of life, which improved after endodontic treatment, Changes in the OHIP-14 was associated with changes in patient self-rating oral health status $(P<$ $.001)$, which was also associated with changes in PAI scores $(P<.05)$ There is significantly improvement in all subscales in which treatment provided by Endodontists followed by Post graduates \& General Dentists.

Conclusions: Endodontic treatment improves quality of life. The OHIP-17 measure is both sensitive and responsive to endodontic treatment. Satisfaction was significantly better when endodontic treatment was provided by Endodontists followed by Postgraduate students and General dentists.

Keywords: Endodontists, Endodontic treatment(ET), Oral Health Impact Profile (OHIP), Postgraduates(PG), Periapical Index (PAI), Root canal therapy (RCT),Satisfaction outcome.
\end{abstract}

\section{Introduction}

"Quality of life is concerned with the degree to which a person enjoys the important possibilities of life" [1]. Dental patients usually, have two major concerns when deciding a root canal therapy, i.e time and pain. Pain is the most common reason for which a patient comes to a dentist for treatment and it also remains the most common reason for refusal to avail to root canal therapy. Endodontic problems (with clinical evidence 
of pulp and/or periapical tissue problems) are common and key reasons for dental care [3][4]. Underpinning the demand for endodontic treatment is the growing recognition that endodontic problems have an impact on quality of life.[2][5].

Quality of life instruments are valuable because they measure the population's perception of the impact of oral disorders on well-being. There has been limited study of patient reported outcomes aside from pain [9]. There are seven conceptual dimensions of oral health: functional limitation, physical pain, psychological discomfort, physical disability, psychological disability, social disability, and handicap [10].

One instrument used to assess quality of life in relation to oral disorders is the Oral Health Impact Profile (OHIP), developed in Australia by Slade and Spence[12]. The semantic differential scales in particular, first introduced by Osgood et al. [11], can be used to obtain ratings of endodontic treatment (ET). Cost, pain etc are the factors that might impact patient satisfaction with ET. Thus, the present study was conducted to assess impact of endodontic disease and treatment on the quality of life of patients and patient's satisfaction in relation to endodontic treatment. and examine the association of these outcomes with the treatment provider (General Dentists, Postgraduates and Endodontist).

\section{Methods}

The present cross sectional study was carried out among 250 patients selected from OPD, in Department of Conservative Dentistry and Endodontics, Government Dental College and hospital Nagpur. Ethical clearance was obtained from the institutional Ethics Committee. Written Informed consent was obtained from all the patients prior to the start of the study. Inclusion criteria were patients with clinical evidence of pulp and/or periapical tissue problems deemed to require root canal therapy, Adults 16 years and older. Patients of Indian ethnicity who could read local regional language.. Exclusion criteria applied were as Patients with serious medical conditions for which they were hospitalized in the past year and/or taking medication for their condition that required consultation with a physician before dental treatment with physical disabilities and communication difficulties noted on their record.

For the sample size requirement, a reference was made to a case-control study of OHQoL among subjects requiring endodontic treatment versus a control group in periodontal maintenance [5]. The case-control study identified that there was a $41 \%$ difference in the short form of the Oral Health Impact Profile (OHIP-14) scores between the case and control subjects. The intended sample size was calculated to be 190 , using $80 \%$ power and alpha error at 5\%, with anticipated 55\% prevalence of at least one impact on OHRQo. Considering a potential dropout rate of $25 \%$ over the 6-month period, 250 patients were selected for the study .

In the single blind randomly clinical study, the patients were then randomly divided into 3 groups $(\mathrm{n}=$ 100) which were treated by Postgraduate students, $(\mathrm{n}=100)$ by general dentists, $(\mathrm{n}=50)$ by Endodontists. 250 patients were randomly selected and assessed before, immediately after and 1 month ,6 month after root canal treatment. Data were collected through a self-administered questionnaire which was distributed to the patients before treatment, immediately after,1month and 6month after root canal treatment. Information was gathered regarding sociodemographic characteristics of patients including age, sex ,education ,area . Patient education was categorised into: primary school level or no education, secondary school level and college/university level of education (Bernabe et al., 2011).

Patients' OHQoL was assessed by using 1 of the most sophisticated and widely used measures - the OHIP-14[12]: The OHIP-17 consists of 17 questions arranged over 7 domains (physical functioning, physical pain, physiological disability, physical disability, psychological disability, social disability, and handicap) based on the World Health Organization's theoretic model of disease-impairment disability- handicap adapted for oral health by Locker [10]. (Table 1).

The questionnaire also included seven semantic differential scales aimed at assessing each subject's level of satisfaction withthe ET(s) received and asked to choose one of the following listed factors that caused the greatest dissatisfaction for each ET received: cost, time involved, pain during the procedure, pain after the procedure, poor aesthetics of the treated tooth, poor chewing ability on the treated tooth, other, or none..

It included additional general questions use about the sociodemographic characteristics of the studied population and to elicit the level of training of the provider for each ET (Endodontist or Postgraduates or 
General dentists )and determine the subjects' perception of and satisfaction with their oral health, both pre- and postoperatively; and the subjects' satisfaction with the decision to have ET rather than extraction.

Quality of life measures included responses made on five-point Likert scales and were coded as follows: $4_{\text {_ }}$ very often; $3_{\text {_ }}$ fairly often; $2_{\text {_ }}$ occasionally; $1_{\text {_ }}$ hardly ever; and $0_{-}$never. The mean "impact value" was tabulated from the Likert scale responses for each item to reflect the preoperative impact of the item on the subjects' daily lives..5-point Likert scale with overall treatment responses ranging from ' 5 'much better," 4 'somewhat better," 3" "no different," '2'somewhat worse," 1 "much worse at the 1-month and 6 month review appointment.

Marathi is the regional language of Nagpur; hence, the questionnaire was translated into Marathi language. The validity was checked by a back translation method, involving blind retranslation into English. The validity of translation was verified by experts in both languages. Cronbach's coefficient _ scores of 0.60 or more indicate good to excellent reliability, where all questions work well together. (Bland and Altman, 1997).

Table 1. Conceptual dimensions and quality of life items included in the instrument

\begin{tabular}{|l|l|}
\hline Conceptual Dimension & Item \\
\hline Functional limitation & $\begin{array}{l}\text { Have you had trouble pronouncing words because of your teeth and mouth? } \\
\text { Have you felt that your sense of taste has worsened because of your teeth or mouth }\end{array}$ \\
\hline Physical pain & $\begin{array}{l}\text { Have you had painful aching in your mouth? } \\
\text { Have you found it uncomfortable to eat any foods because of your teeth or mouth? } \\
\text { Have you had to alter the temperature of the foods that you eat because of your teeth or } \\
\text { mouth? }\end{array}$ \\
\hline $\begin{array}{l}\text { Psychological } \\
\text { discomfort }\end{array}$ & $\begin{array}{l}\text { Have you been self-conscious because of your teeth or mouth? } \\
\text { Have you felt tense because of your teeth or mouth? }\end{array}$ \\
\hline Physical disability & $\begin{array}{l}\text { Has your diet been unsatisfactory because of your teeth or mouth? } \\
\text { Have you had to interrupt meals because of your teeth or mouth? }\end{array}$ \\
\hline $\begin{array}{l}\text { Psychological } \\
\text { disability }\end{array}$ & $\begin{array}{l}\text { Have you found it difficult to relax because of your teeth or mouth? } \\
\text { Have you found it difficult to fall asleep because of your teeth or mouth? } \\
\text { Have you ever been awakened by problems with your teeth or mouth? } \\
\text { Have you been embarrassed because of your teeth or mouth? }\end{array}$ \\
\hline Social disability & $\begin{array}{l}\text { Have you been irritable with other people because of your teeth or mouth? } \\
\text { Have you had difficulty doing your usual jobs because of problems with your teeth or mouth? }\end{array}$ \\
\hline Handicap & $\begin{array}{l}\text { Have you felt that life in general was less satisfying because of your teeth or mouth? Have } \\
\text { you been totally unable to function because of your teeth or mouth? }\end{array}$ \\
\hline
\end{tabular}

Statistical analysis was performed using SPSS v16. Association between 'sociodemographic characteristics and patient OHRQoL were investigated using chi-square test. Variables which showed significant association with patient OHRQoL in bivariate analysis, were included in multivariate analysis. Multivariate analysis was applied using multiple logistic regression (enter method) with high OHRQoL as outcome measure One way ANOVA test with post-hoc Tukey's test_was used for comparison mean OHIP scores between the patients treated by endodontists, PG students \& general dentist.

PAI changes between baseline and the 6-month postobturation review visit were categorized as follows: No change $=0$, PAI score change of $1=1$, PAI score change of $2=2$.

\section{Results}

250 patients with endodontic disease met with the inclusion and exclusion criteria. There was no significant difference in the sociodemographic status or clinical oral health status of those who completed the study versus those recruited as baseline.(Table 2)

Table 2: Sociodemographic distribution of patients

\begin{tabular}{|l|l|l|l|l|l|l|}
\hline & & \multicolumn{2}{|l|}{ Doctor } & Total & \multirow{2}{*}{ P Value } \\
\hline & & PG & Dentist & Endodontist & & \multirow{2}{*}{ Sex } \\
\cline { 1 - 5 } & Male & 51 & 63 & 23 & 137 & \\
\cline { 3 - 6 } & & $37.2 \%$ & $46.0 \%$ & $16.8 \%$ & $100.0 \%$ & \\
\hline
\end{tabular}


Evaluation of Oral Health Related Quality of Life and Satisfaction Outcome of Endodontic ...

\begin{tabular}{|c|c|c|c|c|c|c|}
\hline & Female & 49 & 37 & 27 & 113 & \multirow{5}{*}{0.08} \\
\hline & & $43.4 \%$ & $32.7 \%$ & $23.9 \%$ & $100.0 \%$ & \\
\hline \multirow[t]{6}{*}{ Education } & Primary & & & & & \\
\hline & & $39.1 \%$ & $37.7 \%$ & $23.2 \%$ & $100.0 \%$ & \\
\hline & Middle & $\begin{array}{l}34 \\
32.4 \%\end{array}$ & $\begin{array}{l}53 \\
50.5 \%\end{array}$ & $\begin{array}{l}18 \\
17.1 \%\end{array}$ & $\begin{array}{l}105 \\
100.0 \%\end{array}$ & \\
\hline & High & $\begin{array}{l}18 \\
47.4 \%\end{array}$ & $\begin{array}{l}20 \\
52.6 \%\end{array}$ & $\begin{array}{l}0 \\
.0 \%\end{array}$ & $\begin{array}{l}38 \\
100.0 \%\end{array}$ & \multirow{5}{*}{$<0.001$} \\
\hline & Hsc & $\begin{array}{l}20 \\
66.7 \%\end{array}$ & $\begin{array}{l}1 \\
3.3 \%\end{array}$ & $\begin{array}{l}9 \\
30.0 \%\end{array}$ & $\begin{array}{l}30 \\
100.0 \%\end{array}$ & \\
\hline & $\begin{array}{ll}\text { Degree } & \text { Or } \\
\text { Higher } & \end{array}$ & $\begin{array}{l}0 \\
.0 \%\end{array}$ & $\begin{array}{l}0 \\
.0 \%\end{array}$ & $\begin{array}{l}6 \\
100.0 \%\end{array}$ & $\begin{array}{l}6 \\
100.0 \%\end{array}$ & \\
\hline \multirow[t]{2}{*}{ Area } & Urban & $\begin{array}{l}51 \\
37.8 \%\end{array}$ & $\begin{array}{l}59 \\
43.7 \%\end{array}$ & $\begin{array}{l}25 \\
18.5 \%\end{array}$ & $\begin{array}{l}135 \\
100.0 \%\end{array}$ & \\
\hline & Rural & $\begin{array}{l}49 \\
42.6 \%\end{array}$ & $\begin{array}{l}41 \\
35.7 \%\end{array}$ & $\begin{array}{l}25 \\
21.7 \%\end{array}$ & $\begin{array}{l}115 \\
100.0 \%\end{array}$ & \\
\hline \multirow[t]{2}{*}{ Total } & & 100 & 100 & 50 & 250 & \multirow[b]{2}{*}{0.42} \\
\hline & & $40.0 \%$ & $40.0 \%$ & $20.0 \%$ & $100.0 \%$ & \\
\hline
\end{tabular}

$\mathrm{P}<0.05$ - significant

Table 2 shows Statistical analyses of the sociodemographic characteristics revealed that they were suitably matched with respect to age, gender, family income, education level,

Table 3: Comparison of mean difference scores of OHIP subscales between patients treated by PG Students,

\begin{tabular}{|c|c|c|c|c|c|}
\hline $\begin{array}{c}\text { OHIP } \\
\text { DOMAIN }\end{array}$ & $\begin{array}{l}\text { Treatment } \\
\text { provider }\end{array}$ & $\begin{array}{l}\text { Mean difference (1 } \\
\text { month- } 6 \text { month ) }\end{array}$ & SD & Sig. & post-hoc \\
\hline $\begin{array}{l}\text { Functional } \\
\text { Limitations }\end{array}$ & $\begin{array}{l}\text { PG } \\
\text { General dentist } \\
\text { Endodontist }\end{array}$ & $\begin{array}{l}11.02 \\
9.11 \\
11.58\end{array}$ & $\begin{array}{l}0.84 \\
1.59 \\
0.61\end{array}$ & $\begin{array}{l}06 \\
\text { Ns }\end{array}$ & $\begin{array}{l}\text { PG= Endodontist = General } \\
\text { Dentists }\end{array}$ \\
\hline $\begin{array}{r}\text { Psychological } \\
\text { Discomfort }\end{array}$ & $\begin{array}{l}\text { PG } \\
\text { General dentist } \\
\text { Endodontist }\end{array}$ & $\begin{array}{l}5.0100 \\
3.3500 \\
4.0500\end{array}$ & $\begin{array}{l}0.49 \\
0.63 \\
0.19\end{array}$ & .003 & $\begin{array}{l}\text { PG }>\text { Endodontist }= \\
\text { General Dentists }\end{array}$ \\
\hline $\begin{array}{l}\text { Physical } \\
\text { disability }\end{array}$ & $\begin{array}{l}\text { PG } \\
\text { General dentist } \\
\text { Endodontist }\end{array}$ & $\begin{array}{l}8.1500 \\
6.1300 \\
11.1000\end{array}$ & $\begin{array}{l}0.75 \\
1.47 \\
0.40\end{array}$ & .01 & $\begin{array}{l}\text { Endodontist }>\text { PG }>\text { General } \\
\text { Dentists }\end{array}$ \\
\hline $\begin{array}{l}\text { Psycological } \\
\text { Disability }\end{array}$ & $\begin{array}{l}\text { PG } \\
\text { General dentist } \\
\text { Endodontists }\end{array}$ & $\begin{array}{l}7.6200 \\
7.4400 \\
8.2500\end{array}$ & $\begin{array}{l}0.68 \\
1.30 \\
0.49\end{array}$ & $\begin{array}{l}.06 \\
\mathrm{~ns}\end{array}$ & $\begin{array}{l}\text { Endodontist > PG }= \\
\text { General Dentists }\end{array}$ \\
\hline Social Disability & $\begin{array}{l}\text { PG } \\
\text { General dentist } \\
\text { Endodontist }\end{array}$ & $\begin{array}{l}2.9600 \\
2.8400 \\
3.3000\end{array}$ & $\begin{array}{l}0.55 \\
0.75 \\
0.37\end{array}$ & .02 & $\begin{array}{l}\text { Endodontist }>\text { PG }= \\
\text { GeneralDentists }\end{array}$ \\
\hline Handicap & $\begin{array}{l}\text { PG } \\
\text { General dentist } \\
\text { Endodontist }\end{array}$ & $\begin{array}{l}3.3100 \\
1.8500 \\
2.7400\end{array}$ & $\begin{array}{l}1.08 \\
1.08 \\
0.28\end{array}$ & $<0.001$ & $\begin{array}{l}\text { PG> endodontist > General } \\
\text { Dentists }\end{array}$ \\
\hline Physical Pain & $\begin{array}{l}\text { PG } \\
\text { General dentist }\end{array}$ & $\begin{array}{l}10.1200 \\
8.3500\end{array}$ & $\begin{array}{l}0.64 \\
1.31\end{array}$ & $<0.001$ & $\begin{array}{l}\text { Endodontist > PG > } \\
\text { General Dentists }\end{array}$ \\
\hline
\end{tabular}


Evaluation of Oral Health Related Quality of Life and Satisfaction Outcome of Endodontic ...

\begin{tabular}{|l|l|l|l|l|l|}
\hline & Endodontist & 11.8800 & 0.67 & & \\
\hline Total OHIP & PG & 46.1700 & 2.48096 & 0.04 & Endodontist > PG > \\
& General dentist & 39.5200 & 4.76370 & & General Dentists \\
& Endodontist & 49.1400 & 1.46036 & & \\
\hline
\end{tabular}

Table 3 shows though there were improvement in quality of life after treatment but results is non significant in functional limitations and psychological disability, social disability. While significant results was found in physical pain, psycological discomfort by Postgraduates and physical disability by endodontists Across all 7 domains of the OHIP-14, there was a significant difference in the domain scores over time $(\mathrm{P}<.001)$. Multiplecomparison statistical tests identified a significant difference in all OHIP-14 domain scores between baseline and 1month $(\mathrm{P}<.001)$; the ES of domains ranged from 0.11 to0.09 (functional limitation) to 0.001 (psychological discomfort).

Table 4. Incidence of some impact reported for one or more items in quality of life scale

Table

\begin{tabular}{|l|l|l|l|l|}
\hline & General Dentist & PG & Endodontist & P value \\
\hline Before & $56.5 \%$ & $49.1 \%$ & $52.3 \%$ & \multirow{2}{*}{0.01} \\
\hline After & $52.3 \%$ & $40.3 \%$ & $42.4 \%$ & \\
\hline 1 month & $48 \%$ & $35.6 \%$ & $36.2 \%$ & \\
\hline 6 months & $45 \%$ & $31 \%$ & $30 \%$ & \\
\hline
\end{tabular}

shows that there was significantly improvement in quality of life which were treated by endodontists $(\mathrm{n}=50)$ at baseline from $52.3 \%$ to $30 \%$. Followed by postgraduate students $(\mathrm{n}=100)$ at baseline from $49.1 \%$ to $31 \%$ and general dentists $(\mathrm{n}=100)$ at baseline from $56.5 \%$ to $45 \%$.

Table 5 Comparison of time taken for RCT between PG students, General Dentist \& Endodontist

\begin{tabular}{|c|c|c|c|c|c|}
\hline \multirow[t]{2}{*}{ TIME } & \multicolumn{3}{|l|}{ Doctor } & \multirow[t]{2}{*}{ Total } & \multirow[t]{2}{*}{$P$ value } \\
\hline & PG & General Dentist & endodontist & & \\
\hline \multirow[t]{2}{*}{ Time consuming } & 47 & 82 & 7 & 136 & \\
\hline & $34.6 \%$ & $60.3 \%$ & $5.1 \%$ & $100.0 \%$ & \multirow[t]{4}{*}{$<0.001$} \\
\hline \multirow[t]{2}{*}{ Quick } & 53 & 18 & 43 & 114 & \\
\hline & $46.5 \%$ & $15.8 \%$ & $37.7 \%$ & $100.0 \%$ & \\
\hline \multirow[b]{2}{*}{ TOTAL } & 100 & 100 & 50 & 250 & \\
\hline & $40.0 \%$ & $40.0 \%$ & $20.0 \%$ & $100.0 \%$ & \\
\hline
\end{tabular}

Table 5 shows $60.3 \%$ patient feels RCT is time consuming which were treated by General dentists.

Table 6: Comparison of overall experience of patient with treatment between PG students, General Dentist \& Endodontist

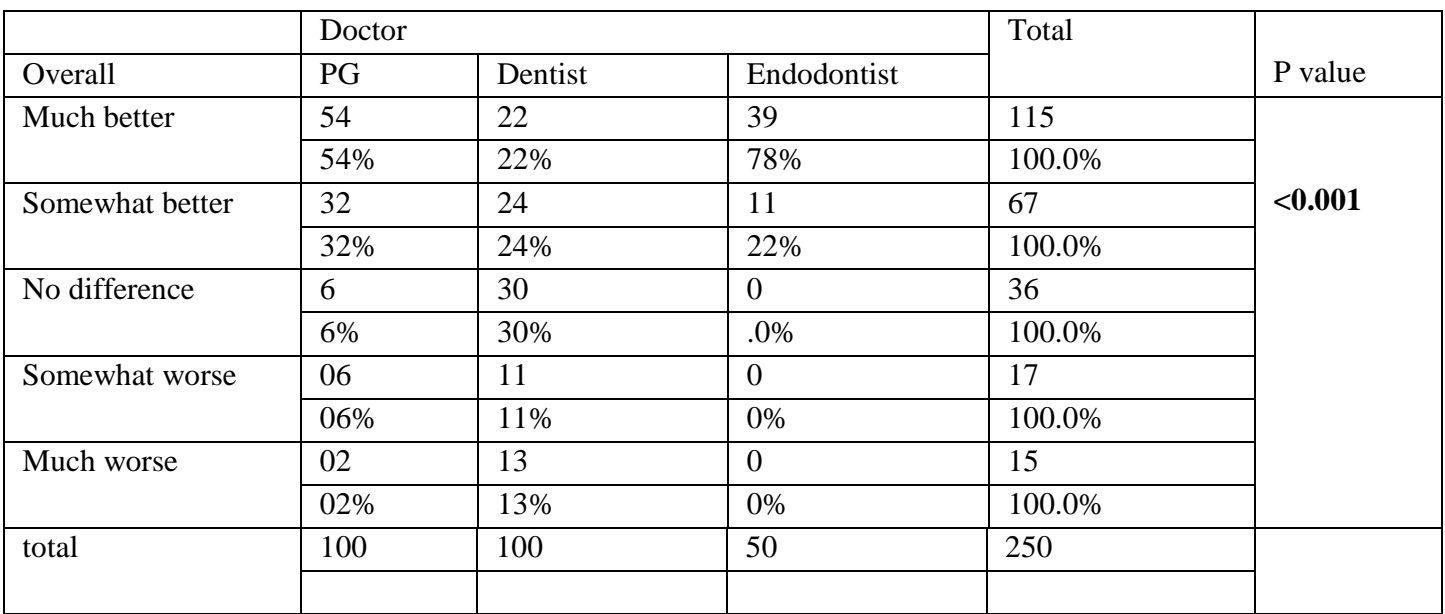


Table 6 shows at the 6-month postobturation review, 78\% patients feel (much better ), significantly higher satisfaction scores provided by endodontists compared to that provided by PG, dentist. There was a significant association between changes in the OHIP-14 summary scores and self ratings of improvement in oral health at the 6-month follow-up ( $<$.001). Compared with baseline PAI ratings (highest value per subject), at 6 months postobturation, $32.7 \%$ (59) remained the same, $39.0 \%$ (66)decreased in PAI rating by 1 , and $41.3 \%$ decreased in PAI rating by 2 . PAI score change (mean \pm SD).

TABle 7 Association Between Observed Changes at The 6-Month Follow-Up In Qol (OHIP-14) And Patients' Global Rating Of Changes Or PAI Score Changes

\begin{tabular}{|c|c|c|c|}
\hline $\begin{array}{l}\text { PAI no } \\
\text { change } \\
(\mathrm{n}=40)\end{array}$ & $\begin{array}{l}\text { PAI } \\
\text { decreased } \\
1(n=80)\end{array}$ & $\begin{array}{l}\text { PAI } \\
\text { decreased } \\
2(n=100)\end{array}$ & $\begin{array}{l}P \\
\text { value }\end{array}$ \\
\hline $3.9+\ldots 10.9$ & $7.3+\ldots 7.9$ & $9.2+\_10.1$ & 048 \\
\hline $0.4+\ldots 1.7$ & $0.6+\ldots 1.5$ & $0.7 \_+1.7$ & .887 \\
\hline $0.9+\_1.9$ & $1.4_{-}+1.7$ & $1.8+2.0$ & .037 \\
\hline $0.9+\_2.2$ & $1.3_{-}+1.7$ & $1.7_{-}+2.2$ & .169 \\
\hline $0.11_{-}+2.1$ & $0.9 \_+1.7$ & $1.3_{-}+2.0$ & .005 \\
\hline $0.7+\_1.8$ & $1.1+\_1.7$ & $1.3_{-}+1.9$ & .372 \\
\hline $0.4+\ldots 1.8$ & $1.0_{-}+1.4$ & $1.1_{-}+1.7$ & .203 \\
\hline $0.5_{-}+1.8$ & $1.0_{-}+1.4$ & $1.3_{-}+1.7$ & .031 \\
\hline
\end{tabular}

Table 7 shows changes in 4 of the 7 OHIP-14 domain scores were associated with improvements in PAI ratings (physical pain, physical disability, and handicap) $(\mathrm{P}<.05)$. There was also an observed gradient of change in the OHIP-17 domain scores with respect to improvement in PAI ratings at 6 months.

\section{Discussion}

The present cross-sectional study found that endodontic problems affect quality of life. This study is the first attempt to assess a population's perception of the impact of endodontic disease on its quality of life and the extent to which such impact can be moderated by ET. Application of the Oral Health Impact Profile (OHIP) demonstrated that disease of pulpal origin affects quality of life with moderate severity, primarily through physical pain and psychological discomfort. Social disability and handicap less affected domain (mean 3.08). An endodontic specific quality of life instrument was specially developed by selecting 17 items from the 49 items included in the OHIP [13]. It was found to have good reliability, validity, and precision . Studies using the OHIP have reported that untreated caries, missing teeth, and loss of periodontal attachment are associated with increasing levels of impact on quality of life and well-being especially among older adults[10]. The follow-up rate to the study was high (at over 95\%), which is comparable with other longitudinal studies of treatment outcome in endodontics [14][15]. Significant changes in OHQoL were observed over the study period indicating the sensitivity of OHIP-17 to endodontic treatment. Compared with pretreatment, it has been shown that the OHIP-17 score improved by 60\% at 1 month (OHIP-14: 11 vs 6) and 70\% (OHIP-14: 11 vs 5) at 6 months. The study results demonstrated that the patient perceived endodontic disease to negatively impact on quality of life.

The most prevalent negative impacts affected the physical pain and psychological disability dimensions - painful aching, discomfort when chewing, and psychological tension were particularly prevalent., functional limitations- unsatisfactory diet., social disability -performing jobs. The results clearly demonstrated that the ET rendered did improve quality of life for all 17 investigated items. It most effectively relieved preoperative painful aching, whereas relief of chewing discomfort and tension was less significant. The analyses revealed that, generally, quality of life was more improved after treatment provided by endodontists and postgraduates than general dentists. This pronounced perception of the negative impact of the disease might greater perceived improvement in quality of life which was provided by endodontists.

In this present study, to establish responsiveness, 2 gold standards of successful endodontic outcomes (ie, transitional ratings of oral health and changes in PAI scores) were used as recommended when interpreting responsiveness ${ }^{14}$. Most patients did perceive that their oral health had improved, but a quarter (at 1 month) and 1 in 5 patients (at 6 months) perceived it to be no better. Nevertheless, there was an observed. gradient of 
changes in the OHIP-17 with respect to perceived changes in oral health (although not always as expected at 1 month with respect to the OHIP-17) and with respect to PAI. Differential outcomes were observed for subjects whose endodontically treated teeth were assigned PAI scores of 3 or higher (which might suggest persistent disease) and those whose PAI scores were 1 or 2 (which might suggest healing).

There is significantly improvement in all subscales in which treatment provided by Endodontists followed by Postgraduates \& General Dentists. Subjects treated by endodontists were significantly more satisfied and indicated the treatment time to be the main reason for the satisfaction. According to the results of a survey conducted by the American Association of Endodontists [16][17], the public's perception of ET is negative because this treatment is associated with pain before, during, and after treatment. our results demonstrated that pain, time was the major cause of dissatisfaction with ET, Due to this patients may not turned up for another visit. $83.3 \%$ \& 17.7 patient feels very painful experience which were treated by General dentists \& PG .Lack of proper knowledge of root canal morphology, proper instrumentation and irrigation protocol ,missed canal, various anatomical variations \& poor quality of obturation can act as nidus of infection which ultimately leads to unfavorable endodontic treatment.

Patients avoid endodontic treatment due to anxiety and fear of pain, resulting in treatment avoidance and eventual tooth loss through extraction. Accurately informing patients about pain associated with endodontic treatment reduces fear of pain. Patient education is critically important. 96\% Patients reported satisfaction with their decision to have ET rather than extraction. Cost is a barrier to RCT. RCT is less invasive, less costly, less time consuming, with low levels of intraoperative pain, and causes a greater reduction in pain ,but initial costs, lifetime costs, cost effectiveness, cost utility. and cost benefit all compare extremely well to the alternatives like extraction and replacement using implants or fixed prostheses.

By identifying all these factors \& acquiring good communication skills, caring, patient education and motivation, the dental community might improve the general public's perception of ET .It improves the oral health related quality of life. Clearly, there are many factors that may influence this and not merely clinical factors per se. Moreover, changes in OHQoL may be associated with oral rehabilitation (after root canal obturation),' OHQoL experiences after root canal therapy (in its broadest sense). Specific details as to tooth reduction, oral rehabilitation, and so on were not recorded, and we recognize this as a limitation of this study.

\section{Conclusion}

Quality of life and satisfaction are important outcomes of dental care. Endodontic treatment improves quality of life .Using quality of life instruments and dental satisfaction scales provides the facility to "bring dentistry into line with contemporary concepts of health care "by highlighting the broader personal and social consequences of oral diseases and disorders. Dentists must strive to reduce anxiety, fear, experienced and remembered pain of patients. Always accurately inform and educate the patients with respect to technical, practical and psychosocial aspects of RCT. Further studies are required to investigate the main sort of changes after endodontic treatment and the key clinical factors (eg, pain, diagnosis, treatment procedure, operator, associated with $\mathrm{OHQoL}$ improvement).

\section{Acknowledgements}

It's my immense pleasure to express my deep sense of gratitude and sincere thanks to my Dean Dr V.K.Hazarey and Dr Manjusha Warhadpande, Professor and Head of Department, Department of Conservative Dentistry and Endodontics, Government Dental College and Hospital ,Nagpur.

\section{REFERENCES}

[1]. Raphael D, Brown I, Renwick R, Rootman I. Quality of life theory and assessment: what are the implications for health promotion. Issues in Health Promotion Series. University of Toronto, Centre for Health Promotion, 1994.

[2]. Dugas NN, Lawrence HP, Teplitsky P, et al. Quality of life and satisfaction outcomes of endodontic treatment., Journal of endodontics ,28(12),2002,819-27

[3]. Eckerbom M, Flygare L, Magnusson T. A 20-year follow-up study of endodontic variables and apical status in a Swedish population. Int Endod J ,2007;40:940-8.

[4]. Kirkevang LL, Vaeth M, Horsted-Bindslev P, et al. Longitudinal study of periapical and endodontic status in a Danish population. Int Endod J 2006;39:100-105. 
[5]. Liu P, McGrath C, Cheung GS. Quality of life and psychological well-being among endodontic patients: a casecontrol study. Aust Dent J 2012;57:493-7.

[6]. Gerritsen AE, Allen PF, Witter DJ, et al. Tooth loss and oral health-related quality of life: a systematic review and meta-analysis. Health Qual Life Outcomes 2010;8:126.

[7]. Levin LG, Law AS, Holland GR, et al. Identify and define all diagnostic terms for pulpal health and disease states. $J$ Endod 2009;35:1645-57.

[8]. S. Acharya and S.R. Srinivasan S.G. Khatri Mothers' sense of coherence and oral health related quality of life of preschool children in Udupi Taluk Community Dental Health ,2014,31, 32-36.

[9]. Iqbal M, Kim S, Yoon F. An investigation into differential diagnosis of pulp and periapical pain: a PennEndo database study. J Endod 2007;33:548-51.

[10]. Locker D. Measuring oral health: a conceptual framework. Community Dent Health 1988;5:3-18.

[11]. Osgood C, Suci G, Tannenbaum P. The measurement of feeling.Urbana: The University of Illinois Press, 1957.

[12]. Slade GD. Derivation and validation of a short-form oral health impact profile. Community Dent Oral Epidemiol 1997; 25:284-90.

[13]. Chapko MK, Bergner M, Green K, Beach B, Milgrom P, Skalabrin N.Development and validation of a measure of dental patient satisfaction. Med Care 1985;23:39-49.

[14]. Tilashalski KR, Gilbert GH, Boykin MJ, et al. Root canal treatment in a population based adult sample: status of teeth after endodontic treatment. J Endod 2004;30:577-81.

[15]. Tsakos G, Allen PF, Steele JG, et al. Interpreting oral health-related quality of life data. Community Dent Oral Epidemiol 2012; 40:193-200.

[16]. Swoboda J, Kiyak HA, Persson RE, et al. Predictors of oral health quality of life in older adults. Spec Care Dentist 2006; 26:137-44.

[17]. American Association of Endodontists. Public Education Report. Surveys document more people choosing root canal therapy over extraction, 1987. 